\title{
Emerging targets in pancreatic cancer: epithelial- mesenchymal transition and cancer stem cells
}

This article was published in the following Dove Press journal:

OncoTargets and Therapy

12 September 2013

Number of times this article has been viewed

\author{
Jason A Castellanos' \\ Nipun B Merchant ${ }^{1-3}$ \\ Nagaraj S Nagathihalli ${ }^{1-3}$ \\ 'Department of Surgery, \\ ${ }^{2}$ Department of Cancer Biology, \\ Vanderbilt University School of \\ Medicine, Nashville, TN, USA; \\ ${ }^{3}$ Vanderbilt-Ingram Comprehensive \\ Cancer Center, Nashville, TN, USA
}

\begin{abstract}
Pancreatic ductal adenocarcinoma is one of the most aggressive solid malignancies and is characterized by poor response to current therapy and a dismal survival rate. Recent insights regarding the role of cancer stem cells (CSCs) and epithelial-mesenchymal transition (EMT) in tumorigenesis have brought further understanding to the field and have highlighted new therapeutic targets. CSCs are a distinct subset of cancer cells, with the ability to differentiate into other cell types and self-renew in order to fuel the maintenance of tumor amplification. Transition of a cancer cell from an EMT leads to increased migratory and invasive properties, and thus facilitates initiation of metastasis. EMT is regulated by a complex network of factors that includes cytokines, growth factors, aberrant signaling pathways, transcription factors, and the tumor microenvironment. There is emerging evidence that the EMT process may give rise to CSCs, or at least cells with stem cell-like properties. We review the key pathways involved in both of these processes, the biomarkers used to identify CSCs, and new therapeutic approaches targeting CSCs and EMT in pancreatic ductal adenocarcinoma.
\end{abstract}

Keywords: epithelial-mesenchymal transition, cancer stem cells, tumor microenvironment, pancreatic ductal adenocarcinoma

\section{Background}

Pancreatic ductal adenocarcinoma (PDAC) is one of the major causes of cancer death worldwide, responsible for an estimated 227,000 deaths each year. At the time of diagnosis, less than $20 \%$ of the patients diagnosed with PDAC present with localized disease amenable to surgical resection, while $40 \%$ present with locally advanced, unresectable disease; the remaining patients already suffer from distant metastases. ${ }^{1,2}$ Treatment strategies have not succeeded in significantly extending patient survival, and clinical outcome has not improved substantially over the past 35 years; the overall 5-year survival rate remains dismal, at around 5\%. ${ }^{3}$ The ability of PDAC to metastasize in early stages is a primary reason for its lethality. Evidence suggests that this process may be mediated by cancer stem cells (CSCs) as well as the ability of cells to undergo epithelial-mesenchymal transition (EMT). ${ }^{4}$ Recent insights regarding the role of CSCs and EMT have brought further understanding to the field by identifying novel signaling pathways involved in tumorigenesis and tumor progression and have highlighted new potential therapeutic targets.

\section{Cancer stem cells}

CSCs have been identified as a distinct subset of cancer cells, with unique properties that differentiate them from the majority of cancer cells comprising a tumor. 
While unrestrained proliferation and resistance to apoptosis are hallmarks of cancer cells, CSCs are distinct in their ability to self-renew, differentiate into other cell types, and form tumors in immunodeficient mice. ${ }^{5}$ These properties of CSCs fuel the maintenance of tumor amplification and tumor mass. ${ }^{6,7}$ This distinct population was initially identified in leukemias, with subsequent identification in solid malignancies of the breast, lung, prostate, colon, brain, head and neck, and liver, as well as in PDAC. ${ }^{8-13}$

\section{Stem cell subpopulations in pancreatic cancer}

Identification of CSCs is based upon the expression of cell surface molecules. These molecules, however, are not uniform across tumor types and are the topic of much debate. The first subpopulation of pancreatic CSCs was identified using knowledge of surface markers based on studies of tumorigenic breast cancer cells. ${ }^{14} \mathrm{Li}$ et al identified a subpopulation of cells derived from human tumors that had cell surface expression of CD44, CD24, and epithelial-specific antigen (ESA) (Figure 1). ${ }^{15}$ They demonstrated that while only $0.2 \%-0.8 \%$ of tumor cells had the CD $44+\mathrm{CD} 24+\mathrm{ESA}+$ phenotype, injection of as few as 500 of these cells formed tumors that recapitulated the architecture of human PDAC from which they were derived. ${ }^{15}$ While this phenotype has clearly been demonstrated to identify a CSC subpopulation in PDAC, the functional significance of these markers is not entirely clear. These proteins may facilitate cell-cell interactions, modulate signaling pathways (CD44 promotes c-MET activity and inhibits Hippo signaling; ESA upregulates c-myc and cyclin A/E) (Figure 1), or they may be a byproduct of transcriptional networks regulating the stem-cell properties of the cells. ${ }^{16-21}$

Subsequent studies have demonstrated that CD133+ cells isolated from human PDAC tumors were also highly tumorigenic and resistant to gemcitabine treatment. ${ }^{22}$ Analysis of resected PDAC specimens from 80 patients revealed that CD133 expression was associated with a significantly lower 5-year survival rate $(P=0.0002)$ compared to tumor specimens that lacked CD133. ${ }^{23}$ The function of CD133 is not known, but it is expressed in non-CSCs as well as CSCs in other malignancies. ${ }^{24-27}$ In normal pancreatic tissue, CXCR4 and its ligand stromal-derived factor-1 (SDF-1) are necessary for the maintenance of pancreatic ductal cell survival, proliferation, and migration during pancreatic organogenesis and regeneration. ${ }^{28}$ In the CSC population, SDF-1 expressed on CD133+ cells with high metastatic potential, and it is also expressed at the invasive edge of tumors. ${ }^{22}$ This suggests the

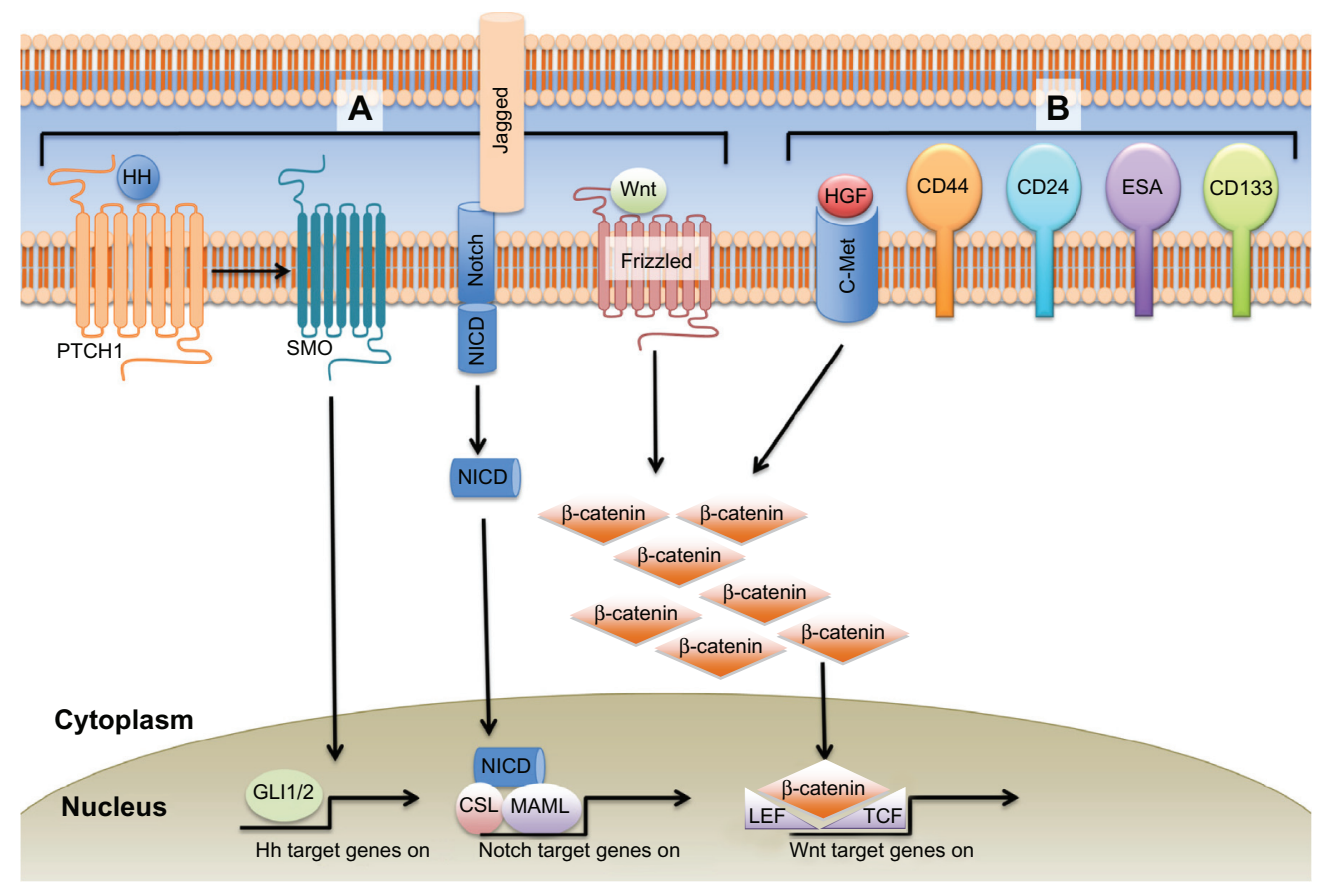

Figure I EMT signaling pathways and CSC markers in pancreatic cancer.

Notes: (A) Hedgehog, Notch, and Wnt signaling promote EMT, and are also active in pancreatic CSCs. (B) CSC surface markers CD44, CD24, and ESA may promote cell-to-cell interaction. The c-Met tyrosine kinase receptor binds HGF and is a marker of tumorigenicity. The function of CDI33 and ALDH (not shown) in CSC regulation is not known.

Abbreviations: ALDH, aldehyde dehydrogenase I; CSC, cancer stem cell; EMT, epithelial-mesenchymal transition; ESA, epithelial-specific antigen; HGF, hepatocyte growth factor. 
existence of two distinct phenotypes of CSCs: stationary (eg, residing in the tumor bulk) and migratory (eg, metastatic cells).

Aldehyde dehydrogenase 1 (ALDH) expression has also been shown to identify PDAC cells with stem cell-like properties - high tumorigenic potential and characteristics of EMT. ${ }^{28}$ Additionally, ALDH+ cells were identified in metastatic lesions arising from primary tumors without ALDH expression, and ALDH+ staining of the primary tumor was associated with a decreased median survival (14 versus 18 months, $P=0.05$ ). In vitro studies have since demonstrated that ALDH+ cell populations have significantly enhanced tumorigenicity while ALDH+CD44+CD24+ cells did not exhibit this property, highlighting the fact that there is currently no universal marker that identifies pancreatic $\mathrm{CSCs}^{29}$ The function of ALDH in regulating CSCs is not known, but in normal tissues it plays a central role in ethanol and cyclophosphamide metabolism as well as in retinoic acid biosynthesis. $^{30}$

Another potential marker of pancreatic CSCs is c-Met, a receptor tyrosine kinase for hepatocyte growth factor (HGF) that has been shown to promote chemoresistance and malignancy (Figure 1). ${ }^{31}$ Initial work by Li et al based on the observation that c-Met is expressed in normal mouse pancreatic stem cells led to the discovery that c-Met-expressing cells were as tumorigenic as CD44+CD24+ESA+ cells, and also more tumorigenic than CD133+ cells. ${ }^{32}$ Of the various subpopulations of cells, they found that CD44+ cells with high expression of c-Met had the highest tumorigenic potential and formed tumors that recapitulated the histology of the tumors that they were derived from.

While much attention has been drawn to the markers that identify CSCs, the role of signaling pathway alterations and the tumor microenvironment in CSC differentiation and function are also being actively explored. Pathways that mediate EMT, such as Notch, Wnt and Hedgehog, also may play a role in CSC function and maintenance in PDAC (Figure 2), although the mechanisms of these interactions are not entirely clear. ${ }^{33-36}$ Signal transducer and activator of transcription 3 (STAT3) is a transcription factor that regulates many cellular processes, and has been shown to be required for maintenance of stem cell-like characteristics in other cancers, such as glioblastoma. ${ }^{37-39}$ The interactions that occur within the tumor microenvironment, however, also have an important role in promoting and maintaining tumorigenesis and the CSC population. The tumor microenvironment is comprised of many different cell compartments, including stellate cells, inflammatory cells, endothelial cells, and tumor cells,

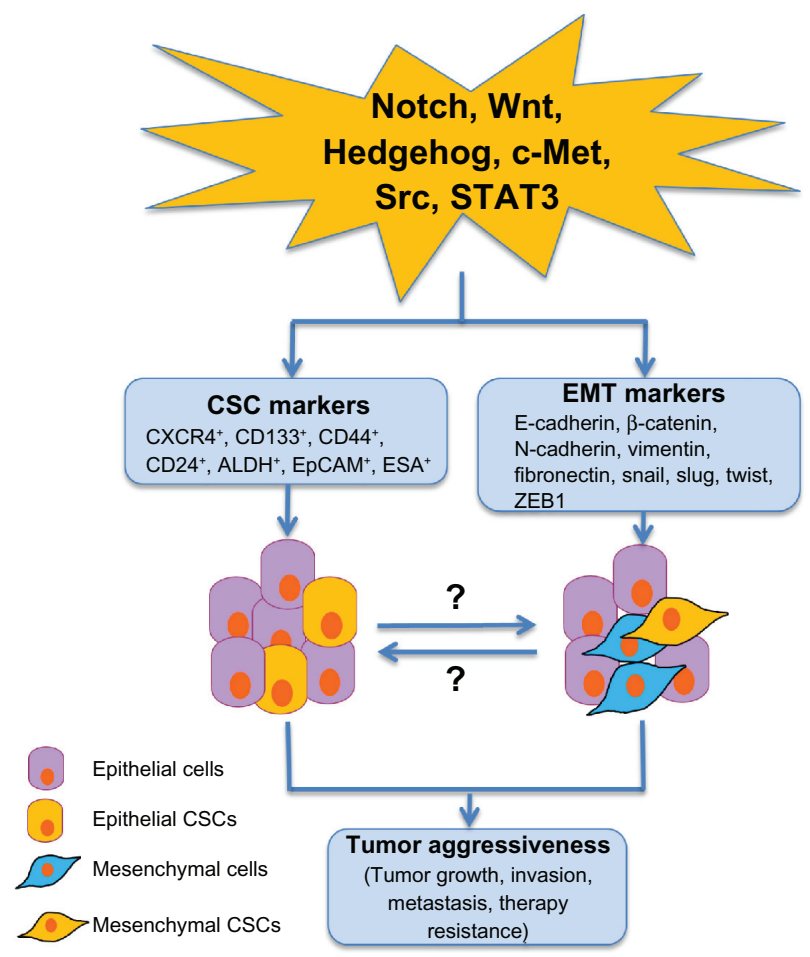

Figure 2 Potential cellular signaling pathways linking to pancreatic CSCs and EMT in tumor aggressiveness.

Notes: The cellular signaling crosstalk and regulation of multiple cellular signaling pathways, including Notch, Wnt, Hedgehog, Src, and STAT3, play critical roles in self-renewal of CSCs, EMT, tumor aggressiveness, metastasis, and therapy resistance. These signaling pathways' activation drives two critical tumor-promoting pathways: (I) increase in CSC markers and (2) EMT promoting markers. These pathways interact with one another, leading to CSC- and EMT-dependent aggressive tumor type. Therefore, targeting these signaling pathways could eliminate pancreatic CSCs and EMT-type cells, which could lead to better treatment outcomes for patients diagnosed with PDAC.

Abbreviations: CSC, cancer stem cell; EMT, epithelial-mesenchymal transition; STAT3, signal transducer and activator of transcription 3; PDAC, pancreatic ductal adenocarcinoma.

which are themselves a heterogenous population comprising CSCs and more differentiated lineages derived from them. One example of the interaction between CSCs and stellate cells, also important in embryogenesis, is through Activin and Nodal, members of the transforming growth factor $\beta$ (TGF $\beta$ ) family. CD133+ CSCs express high levels of Activin and Nodal, while blockade of the Nodal/Activin receptor Alk4/7 reverses the intrinsic chemoresistance to gemcitabine observed in this cell population. ${ }^{40}$ Stellate cells have also been demonstrated to produce Activin and Nodal, which results in increased invasiveness of CSCs. ${ }^{41}$ There is clear evidence, then, that the CSC niche is but one factor driving treatment resistance that characterizes PDAC.

\section{EMT in pancreatic cancer}

Transition of a cancer cell from an epithelial to mesenchymal morphology leads to increased migratory and invasive 
properties, and thus facilitates initiation of metastasis. ${ }^{42}$ This process is utilized in embryonic processes, such as gastrulation, in order to allow partial or complete transition between epithelial and mesenchymal phenotypes. A key feature of EMT is decreased expression of E-cadherin, a transmembrane cell adhesion molecule necessary for maintenance of intercellular contacts and cellular polarity in epithelial tissue, and increased expression of one or more of the mesenchymal markers vimentin, fibronectin, and $\mathrm{N}$-cadherin. Additionally, the loss of E-cadherin expression in PDAC tumors is associated with larger tumors, distant metastases, and increased stage. ${ }^{43}$

We have previously characterized PDAC cell lines as sensitive or chemoresistant based on $\mathrm{IC}_{50}$ values to chemotherapeutics, and also characterized the expression of EMT markers within these cell lines. ${ }^{44}$ BxPC3 cells, which are treatment sensitive, express high levels of E-cadherin and $\beta$-catenin, but have reduced expression of $\mathrm{N}$-cadherin and vimentin. MIApaca2 and PANC1, which are more resistant cell lines, have increased expression of $\mathrm{N}$-cadherin and vimentin and diminished expression of E-cadherin and $\beta$-catenin, indicating that a mesenchymal phenotype may be associated with chemoresistance.

The EMT process is regulated by a complex network of factors that includes cytokines, growth factors, aberrant signaling pathways, transcription factors, and the tumor microenvironment. TGF $\beta$ expression downregulates E-cadherin, and platelet-derived TGF $\beta$ has been demonstrated to cause transition to an invasive mesenchmyal phenotype with enhanced metastatic capability in vivo. ${ }^{45,46}$

The Src family of tyrosine kinases plays a key role in the development of PDAC. Src is overexpressed in up to $70 \%$ of pancreatic cancers. ${ }^{47-49}$ Src has been shown to play a role in E-cadherin regulation and EMT (Figure 2). ${ }^{50} \mathrm{Src}$ activates STAT3 signaling and promotes STAT3 mediated tumor progression and communication within the tumor microenvironment. Constitutively active STAT3 activates the Twist promoter through epidermal growth factor receptor activation and is an important inducer of EMT in cancer cells. ${ }^{51}$ Activation of the Notch pathway decreases E-cadherin expression through upregulation of Slug, while Wnt pathway activation induces EMT either directly or through TGF $\beta$ and other pathways (Figure 2). ${ }^{52-54}$ The Hedgehog pathway is an important embryonic pathway that is associated with many malignancies, including PDAC. ${ }^{55}$ Interaction between the Hedgehog and EMT pathways results in increased invasion, proliferation, and tumor progression, as well as in the promotion of CSCs (Figure 2). ${ }^{53,56-58}$
The transcription factors Snail, Slug, Twist and ZEB1 play a central role in the induction of EMT and downregulation of E-cadherin. ${ }^{59}$ Upregulation of Snail in highly metastatic PDAC cell lines mediates inactivation of E-cadherin and induces EMT through a transcriptional repressor complex containing Snail and histone deacetylase 1 and $2 .{ }^{60}$ Snail, which has high to moderate expression in $78 \%$ of PDAC specimens, appears to be a highly relevant mediator of E-cadherin repression, metastasis promotion, and chemoresistance in PDAC. ${ }^{61,62}$ ZEB1 is a target gene of Snail that represses the expression of E-cadherin through binding of E-boxes in the promoter region, and also through regulation of microRNAs specific for genes relevant in metastasis and migration of CSCs. ${ }^{63}$ Twist1 is an inducer of EMT, and Tsai et al demonstrated that while activation of Twist 1 increases the number of circulating tumor cells, downregulation of Twist 1 led to increased proliferation and a higher number of metastases in an in vivo mouse model of skin cancer. ${ }^{64}$ These results indicate that while EMT promotes stem celllike behavior and dissemination, reversion to an epithelial cell-type may be required to form metastases. Ocana et al identified homeobox factor Prrx1 as an EMT activator that is coexpressed and cooperative with Twist1, but that also suppresses stemness. The loss of Prrx1 was required for metastases in vivo, but in this model EMT and stemness were uncoupled, thus illustrating the complexity of the relationship between EMT and CSCs. ${ }^{65}$

The tumor microenvironment of PDAC is characterized by a dense desmoplastic reaction, also known as stroma, which leads to hypoxia and poor tissue perfusion. Hypoxia leads to upregulation of hypoxia inducible factor $1 \alpha$, which leads to increased expression of Twist. ${ }^{66,67}$ Additionally, the matrix proteins secreted by pancreatic stellate cells, which regulate the fibrotic response, lead to the promotion of EMT and may contribute significantly to metastases. ${ }^{68-71}$ Rather than passively laying down stromal proteins, stellate cells are thought to play an active role in establishing the metastatic site, promoting angiogenesis through secretion of vascular endothelial growth factor, and promoting selfrenewal of CSC through secretion of $\mathrm{HGF}$, as well as Activin and Nodal. ${ }^{72,73}$

\section{EMT-induced CSCs in pancreatic cancer}

There is emerging evidence that the EMT program may give rise to CSCs, or at least cells with stem cell-like properties. As outlined above, CSCs exhibit activation of many pathways involved in EMT. In breast cancer, activation of these 
EMT-related pathways results in increased invasiveness and metastatic potential. ${ }^{74}$ Mani et al were able to induce expression of stem cell markers by either conditionally overexpressing the EMT-inducing transcription factors Snail or Twist, or by exposing the cells to TGF- $\beta 1 .{ }^{75}$ In addition to expression of stem cell markers, these cells also adopted a mesenchymal phenotype and grew into mammospheres more effectively, suggesting that EMT is able to induce the characteristics associated with stem cells. This work identified the possibility that EMT also may have a direct relationship with CSCs, and may induce the CSC phenotype and enhance metastatic ability. Rhim et al have since demonstrated that circulating tumor cells, which are thought to require EMT to extravasate into the blood stream, have a 100-fold increase in CD24+CD44+ expression compared to the source pancreas. ${ }^{76}$

\section{Targeting CSCs and EMT in pancreatic cancer}

Targeting CSCs has been shown to be difficult in other malignancies. To evaluate treatment response in chronic myeloid leukemia, Graham et al showed in peripheral blood samples that even when a significant proportion of dividing cells were killed with chemotherapy, CSCs were able to survive and remain viable in a quiescent state to potentially cause relapse at a later date. ${ }^{77}$ Therapeutic strategies do not specifically target populations of cancer cells, but rather aim to debulk tumors either through cytotoxicity or through targeted inhibition of key signaling pathways. Due to the intrinsic chemoresistance of CSCs, monotherapy with cytotoxic agents, such as gemcitabine, has actually been demonstrated to increase the relative proportion of $\mathrm{c}-\mathrm{Met}^{+}$ CSCs. ${ }^{32}$ Newer agents that target pathways or genes that are upregulated specifically in CSCs, such as c-MET or Alk-4/7, have been shown to reduce the number of CSCs and tumor burden in vivo. ${ }^{32,40}$ Targeting of the stroma with a hedgehog pathway inhibitor in addition to cytotoxic gemcitabine and targeted inhibition of Alk4/7 resulted in a synergistic response in vivo, as defined by progression-free survival and enhanced drug delivery. ${ }^{40}$

Other potential targets include the pathways mediating EMT, such as Notch, Wnt, Hedgehog, Src, and TGF $\beta$. Other compounds, such as Silibinin, target EMT-inducing transcription factors, such as Zeb1, directly. ${ }^{78}$ While there are many clinical trials exploring the possibility of targeting CSCs and/or EMT-related pathways, this treatment strategy is in early stages of development. Other intriguing possibilities include immunotherapy directed against CSC markers, such as ALDH, but this is complicated by the fact that many of these markers can be found on normal stem cells in the hematopoietic system. ${ }^{79}$

\section{Conclusion}

The discovery and characterization of CSCs in PDAC and recent advances in understanding the role of EMT and the tumor microenvironment have led to a greater understanding of tumor behavior and prognosis. Beyond characterization of cell surface markers, however, there is still much that remains unknown about CSCs, including the mechanisms they utilize to maintain their innate chemoresistance. If targeting CSCs is to become a viable strategy, then an understanding of the key signaling pathways involved in CSC maintenance and activity is required. Additionally, understanding the role of EMT in maintaining this niche could aid in the design of therapeutic strategies. While there is currently no effective treatment for PDAC, our increasing understanding of the disease components brings hope for new strategies to target the cells and processes that make PDAC such a difficult disease to treat.

\section{Acknowledgments}

This work was supported by the National Institutes of Health Grants CA161976, Digestive Disease Research Center (DDRC) Translational Award 5P30DK058404-08, and Vanderbilt-Ingram Cancer Center Support Grant 5P30 CA068485-1 (all to Nipun B Merchant), and DDRC Grant P30 DK058404 (to Nagaraj S Nagathihalli).

\section{Disclosure}

The authors report no conflict of interest in this work.

\section{References}

1. Barugola G, Falconi M, Bettini R, et al. The determinant factors of recurrence following resection for ductal pancreatic cancer. JOP. 2007;8(Suppl 1):132-140.

2. Griffin JF, Smalley SR, Jewell W, et al. Patterns of failure after curative resection of pancreatic carcinoma. Cancer. 1990;66(1):56-61.

3. Siegel R, Naishadham D, Jemal A. Cancer statistics, 2013. CA Cancer J Clin. Jan 2013;63(1):11-30.

4. Li Y, Kong D, Ahmad A, Bao B, Sarkar FH. Pancreatic cancer stem cells: Emerging target for designing novel therapy. Cancer Lett. 2012;338(1):94-100.

5. Hanahan D, Weinberg RA. The hallmarks of cancer. Cell. 2000;100(1): $57-70$.

6. Clevers H. The cancer stem cell: premises, promises and challenges. Nat Med. 2011;17(3):313-319.

7. Clarke MF, Dick JE, Dirks PB, et al. Cancer stem cells - perspectives on current status and future directions: AACR Workshop on cancer stem cells. Cancer Res. 2006;66(19):9339-9344.

8. Eppert K, Takenaka K, Lechman ER, et al. Stem cell gene expression programs influence clinical outcome in human leukemia. Nat Med. 2011;17(9):1086-1093. 
9. Tang C, Ang BT, Pervaiz S. Cancer stem cell: target for anti-cancer therapy. FASEB J. 2007;21(14):3777-3785.

10. Ma S, Chan KW, Hu L, et al. Identification and characterization of tumorigenic liver cancer stem/progenitor cells. Gastroenterology. 2007;132(7):2542-2556.

11. O'Brien CA, Pollett A, Gallinger S, Dick JE. A human colon cancer cell capable of initiating tumour growth in immunodeficient mice. Nature. 2007;445(7123):106-110.

12. Kim CF, Jackson EL, Woolfenden AE, et al. Identification of bronchioalveolar stem cells in normal lung and lung cancer. Cell. 2005;121(6):823-835.

13. Lee CJ, Dosch J, Simeone DM. Pancreatic cancer stem cells. J Clin Oncol. 2008;26(17):2806-2812.

14. Al-Hajj M, Wicha MS, Benito-Hernandez A, Morrison SJ, Clarke MF. Prospective identification of tumorigenic breast cancer cells. Proc Natl Acad Sci U S A. 2003;100(7):3983-3988.

15. Li C, Heidt DG, Dalerba P, et al. Identification of pancreatic cancer stem cells. Cancer Res. 2007;67(3):1030-1037.

16. Abel EV, Simeone DM. Biology and clinical applications of pancreatic cancer stem cells. Gastroenterology. 2013;144(6):1241-1248.

17. Litvinov SV, Velders MP, Bakker HA, Fleuren GJ, Warnaar SO. Ep-CAM: a human epithelial antigen is a homophilic cell-cell adhesion molecule. J Cell Biol. 1994;125(2):437-446.

18. Aigner S, Sthoeger ZM, Fogel M, et al. CD24, a mucin-type glycoprotein, is a ligand for P-selectin on human tumor cells. Blood. 1997;89(9):3385-3395

19. St John T, Meyer J, Idzerda R, Gallatin WM. Expression of CD44 confers a new adhesive phenotype on transfected cells. Cell. 1990;60(1): $45-52$.

20. van der Voort R, Taher TE, Wielenga VJ, et al. Heparan sulfate-modified CD44 promotes hepatocyte growth factor/scatter factor-induced signal transduction through the receptor tyrosine kinase c-Met. J Biol Chem. 1999;274(10):6499-6506.

21. Münz M, Kieu C, Mack B, Schmitt B, Zeidler R, Gires O. The carcinoma-associated antigen EpCAM upregulates c-myc and induces cell proliferation. Oncogene. 2004;23(34):5748-5758.

22. Hermann PC, Huber SL, Herrler T, et al. Distinct populations of cancer stem cells determine tumor growth and metastatic activity in human pancreatic cancer. Cell Stem Cell. 2007;1(3):313-323.

23. Maeda S, Shinchi H, Kurahara H, et al. CD133 expression is correlated with lymph node metastasis and vascular endothelial growth factor-C expression in pancreatic cancer. Br J Cancer. 2008;98(8): 1389-1397.

24. Shmelkov SV, St Clair R, Lyden D, Rafii S. AC133/CD133/Prominin-1. Int J Biochem Cell Biol. 2005;37(4):715-719.

25. Singh SK, Clarke ID, Terasaki M, et al. Identification of a cancer stem cell in human brain tumors. Cancer Res. 2003;63(18):5821-5828.

26. Frank NY, Margaryan A, Huang Y, et al. ABCB5-mediated doxorubicin transport and chemoresistance in human malignant melanoma. Cancer Res. 2005;65(10):4320-4333.

27. Miki J, Furusato B, Li H, et al. Identification of putative stem cell markers, CD133 and CXCR4, in hTERT-immortalized primary nonmalignant and malignant tumor-derived human prostate epithelial cell lines and in prostate cancer specimens. Cancer Res. 2007;67(7):3153-3161.

28. Rasheed ZA, Yang J, Wang Q, et al. Prognostic significance of tumorigenic cells with mesenchymal features in pancreatic adenocarcinoma. J Natl Cancer Inst. 2010;102(5):340-351.

29. Kim MP, Fleming JB, Wang H, et al. ALDH activity selectively defines an enhanced tumor-initiating cell population relative to CD133 expression in human pancreatic adenocarcinoma. PLOS ONE. 2011;6(6):e20636

30. Rasheed ZA, Matsui W. Biological and clinical relevance of stem cells in pancreatic adenocarcinoma. J Gastroenterol Hepatol. 2012; 27 Suppl 2:15-18.

31. Gherardi E, Birchmeier W, Birchmeier C, Vande Woude G. Targeting MET in cancer: rationale and progress. Nat Rev Cancer. 2012;12(2): $89-103$.
32. Li C, Wu JJ, Hynes M, et al. c-Met is a marker of pancreatic cancer stem cells and therapeutic target. Gastroenterology. 2011;141(6): 2218-2227. e5.

33. Brabletz S, Bajdak K, Meidhof S, et al. The ZEB1/miR-200 feedback loop controls Notch signalling in cancer cells. EMBO J. 2011;30(4):770-782.

34. Mizuma M, Rasheed ZA, Yabuuchi S, et al. The gamma secretase inhibitor MRK-003 attenuates pancreatic cancer growth in preclinical models. Mol Cancer Ther. 2012;11(9):1999-2009.

35. Wang L, Heidt DG, Lee CJ, et al. Oncogenic function of ATDC in pancreatic cancer through Wnt pathway activation and beta-catenin stabilization. Cancer Cell. 2009;15(3):207-219.

36. Mueller MT, Hermann PC, Witthauer J, et al. Combined targeted treatment to eliminate tumorigenic cancer stem cells in human pancreatic cancer. Gastroenterology. 2009;137(3):1102-1113.

37. Guryanova OA, Wu Q, Cheng L, et al. Nonreceptor tyrosine kinase BMX maintains self-renewal and tumorigenic potential of glioblastoma stem cells by activating STAT3. Cancer Cell. 2011;19(4): 498-511.

38. Sherry MM, Reeves A, Wu JK, Cochran BH. STAT3 is required for proliferation and maintenance of multipotency in glioblastoma stem cells. Stem Cells. 2009;27(10):2383-2392.

39. Kim E, Kim M, Woo DH, et al. Phosphorylation of EZH2 activates STAT3 signaling via STAT3 methylation and promotes tumorigenicity of glioblastoma stem-like cells. Cancer Cell. 2013;23(6):839-852.

40. Lonardo E, Hermann PC, Mueller MT, et al. Nodal/Activin signaling drives self-renewal and tumorigenicity of pancreatic cancer stem cells and provides a target for combined drug therapy. Cell Stem Cell. 2011;9(5):433-446.

41. Lonardo E, Frias-Aldeguer J, Hermann PC, Heeschen C. Pancreatic stellate cells form a niche for cancer stem cells and promote their selfrenewal and invasiveness. Cell Cycle. 2012;11(7):1282-1290.

42. Karamitopoulou E. Tumor budding cells, cancer stem cells and epithelial-mesenchymal transition-type cells in pancreatic cancer. Front Oncol. 2012;2:209.

43. Shin SJ, Kim KO, Kim MK, et al. Expression of E-cadherin and uPA and their association with the prognosis of pancreatic cancer. Jpn J Clin Oncol. 2005;35(6):342-348.

44. Nagaraj NS, Washington MK, Merchant NB. Combined blockade of Src kinase and epidermal growth factor receptor with gemcitabine overcomes STAT3-mediated resistance of inhibition of pancreatic tumor growth. Clin Cancer Res. 2011;17(3):483-493.

45. Labelle M, Begum S, Hynes RO. Direct signaling between platelets and cancer cells induces an epithelial-mesenchymal-like transition and promotes metastasis. Cancer Cell. 2011;20(5):576-590.

46. Bardeesy N, Cheng KH, Berger JH, et al. Smad4 is dispensable for normal pancreas development yet critical in progression and tumor biology of pancreas cancer. Genes Dev. 2006;20(22):3130-3146.

47. Shields DJ, Murphy EA, Desgrosellier JS, et al. Oncogenic Ras/ Src cooperativity in pancreatic neoplasia. Oncogene. 2011;30(18): 2123-2134

48. Lutz MP, Esser IB, Flossmann-Kast BB, et al. Overexpression and activation of the tyrosine kinase Src in human pancreatic carcinoma. Biochem Biophys Res Commun. 1998;243(2):503-508.

49. Nagaraj NS, Smith JJ, Revetta F, Washington MK, Merchant NB. Targeted inhibition of SRC kinase signaling attenuates pancreatic tumorigenesis. Mol Cancer Ther. 2010;9(8):2322-2332.

50. Nagathihalli NS, Merchant NB. Src-mediated regulation of E-cadherin and EMT in pancreatic cancer. Front Biosci (Landmark Ed). 2012;17: 2059-2069.

51. Lo HW, Hsu SC, Xia W, et al. Epidermal growth factor receptor cooperates with signal transducer and activator of transcription 3 to induce epithelial-mesenchymal transition in cancer cells via up-regulation of TWIST gene expression. Cancer Res. 2007;67(19):9066-9076.

52. Leong KG, Niessen K, Kulic I, et al. Jagged1-mediated Notch activation induces epithelial-to-mesenchymal transition through Slug-induced repression of E-cadherin. J Exp Med. 2007;204(12):2935-2948. 
53. Fuxe J, Vincent T, Garcia de Herreros A. Transcriptional crosstalk between TGF- $\beta$ and stem cell pathways in tumor cell invasion: role of EMT promoting Smad complexes. Cell Cycle. 2010;9(12): 2363-2374.

54. Zhou BP, Hung MC. Wnt, hedgehog and snail: sister pathways that control by GSK-3beta and beta-Trcp in the regulation of metastasis. Cell Cycle. 2005;4(6):772-776.

55. Thayer SP, di Magliano MP, Heiser PW, et al. Hedgehog is an early and late mediator of pancreatic cancer tumorigenesis. Nature. 2003;425(6960):851-856.

56. Varnat F, Duquet A, Malerba M, et al. Human colon cancer epithelial cells harbour active HEDGEHOG-GLI signalling that is essential for tumour growth, recurrence, metastasis and stem cell survival and expansion. EMBO Mol Med. 2009;1(6-7):338-351.

57. Feldmann G, Dhara S, Fendrich V, et al. Blockade of hedgehog signaling inhibits pancreatic cancer invasion and metastases: a new paradigm for combination therapy in solid cancers. Cancer Res. 2007;67(5): 2187-2196.

58. Dembinski JL, Krauss S. Characterization and functional analysis of a slow cycling stem cell-like subpopulation in pancreas adenocarcinoma. Clin Exp Metastasis. 2009;26(7):611-623.

59. Peinado H, Olmeda D, Cano A. Snail, Zeb and bHLH factors in tumour progression: an alliance against the epithelial phenotype? Nat Rev Cancer. 2007;7(6):415-428

60. von Burstin J, Eser S, Paul MC, et al. E-cadherin regulates metastasis of pancreatic cancer in vivo and is suppressed by a SNAIL/ HDAC1/HDAC2 repressor complex. Gastroenterology. 2009;137(1): 361-371, 371. e1.

61. Hotz B, Arndt M, Dullat S, Bhargava S, Buhr HJ, Hotz HG. Epithelial to mesenchymal transition: expression of the regulators snail, slug, and twist in pancreatic cancer. Clin Cancer Res. 2007;13(16):4769-4776.

62. Yin T, Wang C, Liu T, Zhao G, Zha Y, Yang M. Expression of snail in pancreatic cancer promotes metastasis and chemoresistance. J Surg Res. 2007;141(2):196-203.

63. Wellner U, Schubert J, Burk UC, et al. The EMT-activator ZEB1 promotes tumorigenicity by repressing stemness-inhibiting microRNAs. Nat Cell Biol. 2009;11(12):1487-1495.

64. Tsai JH, Donaher JL, Murphy DA, Chau S, Yang J. Spatiotemporal regulation of epithelial-mesenchymal transition is essential for squamous cell carcinoma metastasis. Cancer Cell. 2012;22(6):725-736.

65. Ocaña $\mathrm{OH}$, Córcoles R, Fabra A, et al. Metastatic colonization requires the repression of the epithelial-mesenchymal transition inducer Prrx1. Cancer Cell. 2012;22(6):709-724.
66. Satoh K, Hamada S, Kimura K, et al. Up-regulation of MSX2 enhances the malignant phenotype and is associated with twist 1 expression in human pancreatic cancer cells. Am J Pathol. 2008;172(4):926-939.

67. Sun S, Ning X, Zhang Y, et al. Hypoxia-inducible factor-1alpha induces Twist expression in tubular epithelial cells subjected to hypoxia, leading to epithelial-to-mesenchymal transition. Kidney Int. 2009;75(12): $1278-1287$.

68. Masamune A, Watanabe T, Kikuta K, Shimosegawa T. Roles of pancreatic stellate cells in pancreatic inflammation and fibrosis. Clin Gastroenterol Hepatol. 2009;7(Suppl 11):S48-S54.

69. Erkan M, Adler G, Apte MV, et al. StellaTUM: current consensus and discussion on pancreatic stellate cell research. Gut. 2012;61(2): 172-178.

70. Bachem MG, Schünemann M, Ramadani M, et al. Pancreatic carcinoma cells induce fibrosis by stimulating proliferation and matrix synthesis of stellate cells. Gastroenterology. 2005;128(4):907-921.

71. Kanno A, Satoh K, Masamune A, et al. Periostin, secreted from stromal cells, has biphasic effect on cell migration and correlates with the epithelial to mesenchymal transition of human pancreatic cancer cells. Int J Cancer. 2008;122(12):2707-2718.

72. Xu Z, Vonlaufen A, Phillips PA, et al. Role of pancreatic stellate cells in pancreatic cancer metastasis. Am J Pathol. 2010;177(5):2585-2596.

73. Masamune A, Kikuta K, Watanabe T, Satoh K, Hirota M, Shimosegawa T. Hypoxia stimulates pancreatic stellate cells to induce fibrosis and angiogenesis in pancreatic cancer. Am J Physiol Gastrointest Liver Physiol. 2008;295(4):G709-G717.

74. Hugo H, Ackland ML, Blick T, et al. Epithelial-mesenchymal and mesenchymal-epithelial transitions in carcinoma progression. $J$ Cell Physiol. 2007;213(2):374-383.

75. Mani SA, Guo W, Liao MJ, et al. The epithelial-mesenchymal transition generates cells with properties of stem cells. Cell. 2008;133(4): 704-715.

76. Rhim AD, Mirek ET, Aiello NM, et al. EMT and dissemination precede pancreatic tumor formation. Cell. 2012;148(1-2):349-361.

77. Graham SM, Jørgensen HG, Allan E, et al. Primitive, quiescent, Philadelphia-positive stem cells from patients with chronic myeloid leukemia are insensitive to STI571 in vitro. Blood. 2002;99(1):319-325.

78. Wu K, Zeng J, Li L, et al. Silibinin reverses epithelial-to-mesenchymal transition in metastatic prostate cancer cells by targeting transcription factors. Oncol Rep. 2010;23(6):1545-1552.

79. Visus C, Wang Y, Lozano-Leon A, et al. Targeting ALDH(bright) human carcinoma-initiating cells with ALDH1A1-specific $\mathrm{CD}^{+} \mathrm{T}$ cells Clin Cancer Res. 2011;17(19):6174-6184.
OncoTargets and Therapy

\section{Publish your work in this journal}

OncoTargets and Therapy is an international, peer-reviewed, open access journal focusing on the pathological basis of all cancers, potential targets for therapy and treatment protocols employed to improve the management of cancer patients. The journal also focuses on the impact of management programs and new therapeutic agents and protocols on

\section{Dovepress}

patient perspectives such as quality of life, adherence and satisfaction The manuscript management system is completely online and includes a very quick and fair peer-review system, which is all easy to use. Visit http://www.dovepress.com/testimonials.php to read real quotes from published authors. 